\title{
DA ENTREVISTA AO TEXTO BIOGRÁFICO - A CONSTRUÇÃO NARRATIVA DE DADOS EM UMA PESQUISA SOBRE FORMAÇÃO DE PROFESSORES
}

\author{
FROM THE INTERVIEW TO THE BIOGRAPHICAL TEXT - THE NARRATIVE BUILDING OF \\ DATA ON A RESEARCH ABOUT TEACHERS' TRAINING
}

DE LA ENTREVISTA AL TEXTO BIOGRÁFICO - LA CONSTRUCCIÓN NARRATIVA DE DATOS EN UNA INVESTIGACIÓN SOBRE FORMACIÓN DE PROFESORES

Gustavo Lopes Ferreira E-mail: gustavolofer@gmail.com

Tiessa Lorraine Miguel da Silva E-mail: $\underline{\text { tiessa77@gmail.com }}$

Instituto Federal de Educação, Ciência e Tecnologia Goiano (IF Goiano) - Campus Ceres

\section{RESUMO}

\begin{abstract}
Neste artigo realizamos a interpretação de textos biográficos produzidos a partir de entrevistas com estudantes mais velhos do curso de Ciências Biológicas do Instituto Federal Goiano. Esta foi uma estratégia adotada em uma pesquisa de abordagem biográfica, na qual buscamos compreender os sentidos atribuídos à formação inicial pelos licenciandos, a partir de suas histórias de vida. Utilizamos como referenciais teóricos as contribuições de Nóvoa e Finger; Bolívar; Delory-Momberger; Ferrarotti; Josso; Ricoeur. Os dados foram construídos de forma narrativa, por isso a opção pelos textos biográficos como material para interpretação. $\mathrm{Na}$ interpretação construímos uma narração que conjugou elementos tais e quais foram ditos pelos estudantes, ao mesmo tempo em que fizemos descrições interpretativas que vão além dos seus horizontes. Dois principais motivos foram depreendidos: a dialética entre o individual e o coletivo; a demarcação de um modo de conceber o curso superior como superação dos dramas vividos ao longo da vida. Os textos biográficos mostraram como os indivíduos analisam e percebem a realidade, como organizam suas experiências e dão sentido ao que se vive e ao mundo. Percebemos que o curso estudado tem transformado a forma como os alunos mais velhos vivem sua formação e como se relacionam com a mesma.
\end{abstract}

PALAVRAS-CHAVE: Pesquisa biográfica. Formação de professores. Biografia.

\section{ABSTRACT}

In this article we conducted the interpretation of biographical texts produced from semi-structured interviews with older students from the undergraduation course of Biological Sciences of Goiano Federal Institute. That was a strategy taken from a research with a biographical approach in which we try to understand the meanings given to the students' initial training formation from their life stories. As theoretical background we used the supports of Nóvoa and Finger; Bolivar; Delory-Momberger; Ferrarotti; Josso; Ricoeur. The data was built in a narrative way; for this reason we chose the biographical texts as material for interpretation. In the interpretation, we made a narration that combined with elements spoken by the students themselves, at the same time, in which we made interpretative descriptions which go beyond their perspectives. Two major topics have been found: the dialetics between the individual and the collective; the emphasis on the way to face the undergraduation course by overcoming the dramas lived throughout life. The biographical texts showed how the individuals analyze and perceive reality; how they organize their experiences and give meaning to what they live and the world. We realized that the undergraduation course studied has transformed the way the older students experience their formation and how they can relate with it.

KEYWORDS: Biographical research. Teacher formation. Biography. 
En este artículo realizamos la interpretación de textos biográficos producidos a partir de entrevistas con alumnos mayores del curso de Ciencias Biológicas de el Instituto Federal Goiano. Esta fue una estrategia dentro de una investigación con enfoque biográfico, en la cual buscamos comprender los sentidos atribuidos a la formación inicial por los alunos de la licenciatura a partir de sus historias de vida. Utilizamos como referenciales teóricos las contribuciones de Nóvoa y Finger; Bolivar; Delory-Momberger; Ferrarotti; Josso; Ricoeur. Los datos fueron construidos de forma narrativa, por lo que la opción por los textos biográficos como material para interpretación. En la interpretación construimos una narración que conjugó elementos tal y cuáles fueron dichos por los estudiantes, al mismo tiempo, en que hicimos descripciones interpretativas que van más allá de sus horizontes. Dos principales motivos fueron depreendidos: la dialéctica entre lo individual y lo colectivo; la demarcación de un modo de encarar el curso superior como superación de los dramas vividos a lo largo de la vida. Los textos biográficos mostraron cómo los individuos analizan y perciben la realidad, cómo organizan sus experiencias y dan sentido a lo que se vive y al mundo. Percibimos que el curso investigado ha transformado la forma en que los alumnos mayores viven su formación y cómo se relacionan con ella.

PALABRAS-CLAVE: Investigación biográfica. Formación de profesores. Biografia.

\section{APRESENTAÇÃO DA PESQUISA}

Em nossa pesquisa fomos mobilizados pela vontade em conhecer e compreender as pessoas com quem temos nos relacionado cotidianamente, muitas vezes, sem darmos a devida atenção. Quem são essas pessoas? Os estudantes mais velhos do curso de Licenciatura em Ciências Biológicas do Instituto Federal Goiano (IF Goiano) - Campus Ceres.

Que estudantes são esses? Por que os identificamos como mais velhos? Entendemos o termo "mais velho" como uma forma de demarcar a valorização da experiência dos alunos mais velhos no curso superior que, tradicionalmente, são minoria neste nível de ensino.

Uma história foi emblemática para nos levar a investigar esse público, a de um senhor de 61 anos, cujo interesse e desempenho demonstrado durante o curso chamaram nossa atenção. Quais motivos o fazia deixar seu lar, em outra cidade, seus afazeres e pegar lápis, caderno e voltar aos estudos? Estendemos tal indagação a todos os demais alunos, ditos mais velhos, propondo conhecêlos por meio de uma pesquisa acadêmica.

Observamos que é considerável a presença de estudantes mais velhos na Licenciatura em Ciências Biológicas do IF Goiano - Campus Ceres, isto considerando aqueles com 25 anos de idade ou mais. Esta situação reflete uma tendência nacional dos cursos de Biologia que tem quase 34\% dos seus graduandos com idade entre 25 e 65 anos (GATTI; BARRETTO, 2009).

Consideramos que os alunos mais velhos merecem atenção, visto que, este é um público recém-chegado ao curso superior. E ainda, diante da necessidade de se aprofundar o conhecimento que se tem sobre esses sujeitos, acreditando que, possivelmente, vivem suas experiências formativas 
de forma diferenciada, com particularidades que são provenientes da sua história de vida construídas em um determinado contexto sócio-histórico.

A partir dessa compreensão nos lançamos no desafio da investigação, na qual buscamos nas experiências formativas relatadas pelos estudantes mais velhos, compreender as expectativas e os sentidos que estes sujeitos têm atribuído à sua formação, enquanto licenciandos em Ciências Biológicas.

Marcadamente adotamos uma perspectiva de investigação biográfica ao: trazermos a subjetividade dos licenciandos para o centro da investigação; ouvirmos suas vozes e histórias; recolhermos e reconhecermos suas histórias de vida por meio de uma entrevista e posterior textualização; buscarmos interpretar em seus relatos os sentidos para suas experiências singulares que são, ao mesmo tempo, coletivas (sociais). E mais profundamente, por tomarmos as biografias como narrativas que contam quem são esses indivíduos.

Dentre os princípios da abordagem biográfica estão as noções de que "ninguém forma ninguém" e que a formação é, inevitavelmente, um trabalho de reflexão crítica sobre os percursos de vida (NÓVOA, 2010, p. 167). Essas duas “máximas" nos põem a pensar que é a formação o principal alvo do trabalho com as histórias de vida evidenciadas em uma investigação biográfica, em especial na formação de adultos. Isto ressoa completamente em nosso objeto de investigação, no caso a formação inicial de alunos mais velhos do curso de Licenciatura em Ciências Biológicas.

Compreender a formação vivenciada ao longo da graduação na perspectiva dos estudantes mais velhos é o que nos moveu no percurso da investigação. Seus relatos podem ser vistos como "o lugar onde o indivíduo humano toma forma, onde elabora e experimenta sua história de vida" (DELORY-MOMBERGER, 2006, p. 361), como o local em que a formação se efetiva.

$\mathrm{Na}$ formação de adultos desencadeada nos cursos de nível superior ainda impera uma prática distante da vida dos sujeitos aprendentes. A vida, bem como as histórias de vida, não é posta como elemento fundador da formação. Nóvoa (2010) defende que a formação dos adultos não pode ser programada, e que são de fato, eles que formam a si próprios. Tendo isso como horizonte, propomos que se valorizem os saberes trazidos pela experiência dos adultos e que, a partir deles se possam encontrar caminhos formativos que permitam que esses sujeitos se apropriem de seu “patrimônio vivencial”, em uma dinâmica de “compreensão retrospectiva” (NÓVOA, 2010, p. 184). Neste processo não é só a vida que importa, mais ainda, a história que cada um conta para si e para os outros sobre sua vida. 
Os sentidos atribuídos à formação inicial pelos estudantes mais velhos na Licenciatura em Ciências Biológicas foram ativados, por nós investigadores, em um roteiro de entrevista semiestruturado. Como nosso interesse estava nas histórias de vida contadas, fizemos a transformação das respostas obtidas nas entrevistas em textos biográficos. Desta forma, privilegiamos o contar sobre esses sujeitos mais velhos a partir de nossos interesses, respeitando a palavra e autoria do que foi relatado.

Neste artigo, buscamos evidenciar como realizamos uma apropriação da perspectiva biográfica. Gostaríamos de chamar atenção para nosso exercício interpretativo em que trouxemos, em primeiro plano, duas histórias de vida de estudantes mais velhos do curso em questão. De posse de seus textos biográficos postos à releitura e editados pelos autores que realizamos o exercício interpretativo.

\section{REFERENCIAL TEÓRICO}

Em nossa pesquisa, recorrentemente, a fundamentação teórica foi desenvolvida em alguns conceitos que merecem detalhamento. A começar pelas noções de experiência e formação. Jorge Larrosa (2015) aproxima a experiência do campo pedagógico, e com isto, nos pôs a pensar o que ela pode promover na formação. Então, nos pareceu plausível parear experiência e formação. Expliquemos melhor tal ligação em seguida.

Antes mesmo de tomarmos consciência já estamos imersos em processos de formação que são repletos de descontinuidades, incertezas, idas e vindas. A formação põe em evidência nossa constituição social, o viver com outros, em contextos, familiares, escolares, profissional. Estes contextos, segundo Dominicé (2010a) regulam e mediam processos específicos que se imbricam uns nos outros, dando forma a cada história de vida.

Os elementos desses contextos podem ser vistos como condições estruturais que influem sobre nossas vidas e nos enredam numa série de experiências que, com maior ou menor intensidade, são formadoras. Assim, concordamos com Larrosa (2015, p. 28) quando afirma que "é experiência aquilo que nos passa, ou que nos toca, ou que nos acontece, e, ao nos passar, nos forma e nos transforma". Nisto, a formação advinda da experiência é o que nos faz pensar, agir e ser de determinada maneira, ela tem a ver com aquilo que cada um de nós faz do que os outros quiseram, ou não quiseram fazer de nós mesmos (DOMINICÉ, 2010a). 
O conjunto de nossas experiências vividas em diversos tempos e espaços, compartilhados com os outros aponta que a experiência não se reduz ao mero subjetivismo, embora, tenha na subjetividade a sua expressão e significância. A noção de experiência traz as marcas da inserção histórica do sujeito.

A experiência liga uma determinada subjetividade ao contexto social mais amplo, para Ferrarotti (2010) todo indivíduo sintetiza um sistema social, totalizando-o pela mediação de seu contexto imediato, pelos grupos de que faz parte. Então, a experiência tem a ver com aquilo que somos, e somente somos o que somos pelas experiências históricas que vivemos, pelo modo como as vivemos e pelo o que esse tempo nos permite viver (LARROSA, 2015).

A tomada de consciência sobre nossas experiências que podem ser tidas como formadoras, porque nos constituem e nos dão forma, é um desafio contínuo a ser enfrentado por cada um de nós. Encontrar os sentidos da formação, traduzidos em termos de projetos de vida e/ou profissionais é um dos propósitos do trabalho com as histórias de vida (DELORY-MOMBERGER, 2006). Para tal autora as histórias de vida contêm, dentre outras coisas, um fundamento prospectivo, apontando para onde se está indo, é uma projeção do sujeito no futuro. Foi assim que as histórias de vida apareceram como outro conceito potente posto no estudo.

Em nossa investigação o texto biográfico funcionou como um meio para que o sujeito pudesse reencontrar-se com sua história de vida, e assim, perceber os sentidos das experiências que viveu ou está vivendo.

A biografia contém a história que o indivíduo conta para si e para os outros. Encontramos em Paul Ricoeur (2010, p. 129) reflexão semelhante ao considerar que "por meio da história o sujeito se dá a conhecer", o sujeito emerge ou aparece. Daí decorre a importância do ato de narrarse (como acontece no texto biográfico) ou contar-se (como ocorre na entrevista semiestruturada), sendo estes o embasamento ontológico da existência humana.

Ricoeur (2010, p. 129) disse que "contamos histórias porque, afinal, as vidas humanas precisam e merecem ser contadas". Considerando toda a força dessa colocação, em uma atitude de abertura, fomos ao encontro das histórias dos estudantes mais velhos. E assim buscamos nos relatos (primeiramente evocados nas entrevistas e posteriormente, textualizados) por suas representações, valores, conhecimentos, sentimentos, desejos, aprendizagens. Essas representações foram construídas discursivamente, utilizando linguagem própria que revelou a forma como cada um se conta e se vê, ou seja, como dão sentido a sua história, porque não dizer, a sua formação. 
O interesse pelas histórias de vida ou pelo enfoque biográfico-narrativo, termo empregado por Bolívar (2002, p. 5) "reconsidera o papel do investigador e a necessidade de incluir a subjetividade no processo de compreensão da realidade". Ainda para o autor, o modo biográfico de compreensão da realidade leva em conta "a materialidade dinâmica do sujeito, suas dimensões pessoais (afetivas, emocionais, biográficas), que somente podem expressar-se por narrativas biográficas nas Ciências Sociais".

As investigações biográficas podem ser encontradas sob diferentes denominações, "histórias de vida ou método biográfico ou biografias educativas" (NÓVOA; FINGER, 2010, p. 11). Qualquer que seja o termo adotado o certo é que todas tiveram como origem o giro hermenêutico produzido nos anos de 1970 nas Ciências Sociais. A partir deste acontecimento passa-se de "uma instância positivista para uma perspectiva interpretativa, na qual o significado dos atores se converte no foco central da investigação" (BOLÍVAR, 2002, p. 4).

Para Paul Ricoeur (2010) a experiência humana contém uma autêntica demanda narrativa, é como se em nossas experiências houvesse uma estrutura pré-narrativa. Então, as histórias que contamos demonstram nossa imbricação viva com outras histórias, que acontecem conosco antes que nos demos conta, são elas que dão o pano de fundo aquilo que contamos (RICOEUR, 2010). Este mesmo autor considera que é preciso que as histórias contadas possam emergir desse pano de fundo, e com isso, o próprio sujeito que está implicado também emergirá.

Decorre disso a importância da linguagem como condição primordial para que as histórias e seus sentidos possam aparecer, bem como o sujeito da história. Ricoeur (2010) anuncia que é pelo fato de estarmos no mundo e sermos afetados por ele que tentamos nos orientar pela compreensão, e com isto, temos algo a dizer, temos experiências para trazer para a linguagem e para serem compartilhadas. A partir disto, entendemos que a experiência não se dá a conhecer de modo direto, é preciso que ela seja expressa na linguagem.

Numa perspectiva hermenêutica Bolívar (2002, p. 6) expressa que, "os fenômenos sociais podem ser tomados como 'textos', cuja significação é dada pela autointerpretação que os atores atribuem a tais fenômenos". Em decorrência disto, as investigações biográficas preocupam-se em reconstruir os sentidos das histórias, ou melhor, dos textos que os indivíduos contam ou narram (DELORY-MOMBERGER, 2006).

Ao nos filiarmos à abordagem biográfica acabamos por aderir à sua história, aos desafios e as críticas que recaem sobre este método. Consideramos, teórica e metodologicamente, esta 
investigação biográfica por meio dos trabalhos de Nóvoa e Finger (2010), Nóvoa (2013), Bolívar (2002), Delory-Momberger (2006, 2010, 2012), Ferrarotti (2010), Josso (2010) e Ricoeur (2010). Estes foram importantes alicerces para compreendermos o trabalho com as histórias de vida experienciado em nossa investigação.

\section{PERCURSO METODOLÓGICO}

Realizamos a pesquisa no Instituto Federal de Educação, Ciência e Tecnologia Goiano. Esta instituição foi criada por meio da Lei $n^{\circ}$. 11.892, de 29 de dezembro de 2008, compondo 38 Institutos Federais (IFs) (BRASIL, 2008).

Em consonância à lei de sua criação, os IFs deverão destinar $20 \%$ das vagas para cursos de licenciatura, bem como programas especiais de formação pedagógica, com vistas à formação de professores para a educação básica, sobretudo nas áreas de ciências e matemática, assim como para a educação profissional e tecnológica (BRASIL, 2008).

Destacamos duas especificidades que nos parece ser o "carro-chefe" dos IFs: a interiorização e a verticalização do ensino. A interiorização implica a presença desses campi em cidades do interior dos estados brasileiros. Já a verticalização reflete a iniciativa de oferecer cursos que vão desde a Educação Básica de nível médio até a Pós-graduação, algo próximo a uma polivalência.

É nesse contexto sociocultural que se encontra a Licenciatura em Ciências Biológicas do Campus Ceres do IF Goiano, local onde desenvolvemos a pesquisa. Fundada em 1953, a cidade de Ceres se localiza na região do centro-norte goiano possuindo, aproximadamente 20.722 habitantes (IBGE, 2010). Mesmo com uma pequena população, este município é reconhecido como um polo de prestação de serviços de educação e saúde, impactando cidades da região.

O IF Goiano - Campus Ceres está localizado na Rodovia GO-154, Km 03, distando 180 km da capital do Estado, Goiânia. Suas atividades tiveram início histórica e fisicamente com a criação da Escola Agrotécnica Federal de Ceres (EAFCe) no ano de 1994.

A história do curso de Ciências Biológicas nesse Campus se iniciou no ano de 2009. Atualmente o Curso está próximo dos 180 alunos matriculados, com corpo docente estabelecido em número de 15 professores das mais variadas áreas. O curso tem seu funcionamento em horário noturno, com duração de oito semestres e foi criado para atender aos anseios da população. 
A pesquisa está marcada fortemente pelos referenciais do método biográfico. Dominicé (2010b, p. 145) defende que o uso do enfoque biográfico se qualifica por estar "implicado uma relação nova do investigador com seu objeto de investigação". Na verdade, esta implicação pode ser traduzida como uma imbricação entre os sujeitos, e isto é parte integrante da proposta de investigação já que o investigador vê sua própria biografia ser confrontada com as dos investigados (DOMINICÉ, 2010b).

Para garantir a coerência entre nossa prática metodológica e a pesquisa biográfica (DELORY-MOMBERGER, 2012) nos preocupamos em construir os dados de forma narrativa, por isso optamos por uma entrevista semiestruturada que foi, posteriormente, transformada em textos biográficos. Após este tratamento empreendemos um exercício de interpretação do material.

Realizamos uma dupla abordagem diante dos dados que foram levantados: voltamo-nos para os aspectos mais gerais, que ligam os indivíduos ao seu contexto sócio-histórico, próximo a uma paisagem exterior, objetiva (BOLÍVAR, 2002); olhamos ainda para o interior, para as subjetividades dos sujeitos, ou o que seria a paisagem interior (BOLÍVAR, 2002). É na confluência desses olhares que a interpretação aconteceu, fazendo emergir nas histórias aquilo que há de geral no singular, e o que há de singular no geral.

Fizemos a textualização de todas as entrevistas realizadas, somando-se onze. E especificamente com dois estudantes entrevistados (foco de nossas interpretações) devolvemos os textos biográficos para leitura. Ao retornarmos os textos para os entrevistados esperávamos que pudessem se reconhecer na história e reencontrassem os sentidos para seus relatos, ou mesmo que propusessem outros.

$\mathrm{Na}$ entrevista semiestruturada abordamos tanto aspectos objetivos quanto pessoais. Como questões norteadoras perguntamos: área de atividade profissional; motivos que o levou a cursar Biologia; se atuou ou atua como professor; dificuldades enfrentadas para permanecer no curso; incentivo familiar e da sociedade para continuar a estudar; o encontro geracional com estudantes mais jovens e com os professores; o que pretende fazer após a Licenciatura.

$\mathrm{Na}$ transformação das entrevistas em textos biográficos procuramos compor histórias construídas em uma totalidade inteligível, preservando o que foi falado, sem alterar o sentido que os informantes deram aos seus relatos. Ressaltamos que os textos biográficos foram construídos por nós pesquisadores, daí a importância de retorno aos entrevistados como forma de validação do que foi relatado. 


\section{INTERPRETAÇÃO DOS TEXTOS BIOGRÁFICOS}

Ao longo da pesquisa fomos compreendendo as entrevistas de modo narrativo, como se elas contassem uma história sobre a vida singular de cada entrevistado. Nestas histórias estão contidas as representações que cada um faz de si mesmo, suas ideias, os valores sociais que constituem o sujeito (FONTOURA, 2013). Para Bauer e Gaskell (2015, p. 103), as narrativas nos dão acesso privilegiado às diferentes perspectivas dos informantes. Foi assim que buscamos compreender tais perspectivas de modo contrastado e ao mesmo tempo, de forma a perceber as consonâncias que ligavam os indivíduos a uma totalidade.

Apoiamo-nos no trabalho de Bolívar (2002) como referencial norteador para a interpretação dos dados. Este autor sustenta um "modo narrativo propriamente dito" como forma de compreensão dos dados narrativo-biográficos. Nesta perspectiva, parte-se do princípio de que as ações humanas são únicas e não repetíveis, dirigindo-se a suas características distintivas. Fizemos uma reapropriação disto, apresentando e interpretando os dados construídos de forma narrativa, costurando em uma trama única as diferentes perspectivas abertas pelos textos biográficos.

Apropriamo-nos do pensamento de Bolívar (2002) ao buscarmos construir uma narração que conjugou elementos tais e quais foram ditos pelos estudantes, ao mesmo tempo, em que não renunciamos em fazer descrições interpretativas que foram além dos horizontes dos interpretados.

No processo interpretativo entendemos que "os significados, primeiramente, são dados pela autointerpretação que os sujeitos relatam em primeira pessoa, onde a dimensão temporal e biográfica ocupa uma posição central” (BOLÍVAR, 2002, p. 4). Logo, nas biografias dos entrevistados já estão contidos a autointerpretação sobre suas histórias de vida, evidenciado pelo estabelecimento de relações entre os diferentes momentos da vida, de explicações de fatos, acontecimentos e ocasiões que marcaram suas trajetórias. O que fizemos neste texto foi reconstruir as histórias de modo articulado, propondo sentidos particulares e contingentes, até alcançarmos uma interpretação possível.

4.1. Um exercício interpretativo dos textos biográficos

A interpretação carrega a perspectiva de alguém, contendo marcas de suas bagagens, em outras palavras, de seus referenciais, valores, crenças, pré-conceitos. Logo, nosso exercício interpretativo se constitui apenas como uma possibilidade de leitura do "mundo do texto"

\begin{tabular}{l|l|l|l|l|l} 
@ C Revista Triângulo & Uberaba, Minas Gerais & v.12 & n.1 & p. 3-23 & 2019
\end{tabular}


(RICOEUR, 2010, p. 137) aberto pelos textos dos nossos personagens. Procuramos construir uma trama no sentido de entrelaçar nosso horizonte respeitando o horizonte dos participantes.

Dentre as histórias contadas pelos acadêmicos durante as onze entrevistas, duas nos chamaram a atenção. Estes relatos nos tocaram e nos fez ter um olhar diferente sobre a vida desses sujeitos. Quem sabe essas histórias nos tenham transformado. É por isso que decidimos colocá-las em destaque neste texto, tomando-as como "histórias-tipo" que funcionam como emblemas da experiência formativa vivida pelo grupo dos estudantes mais velhos no curso de Ciências Biológicas do IF Goiano do Campus Ceres.

As duas histórias de vida, tema de nossa interpretação, foram para nós experiência no sentido de que transformaram o que já sabíamos ou imaginávamos saber sobre os alunos mais velhos. Ao mesmo tempo em que são expressões de sujeitos únicos, essas histórias destacam a pertença social desses indivíduos, como destaca Ferrarotti (2010).

A interiorização é uma marca importante que os Institutos Federais carregam, tendo em vista que, um dos referenciais de sua política é ofertar educação pública em regiões distantes dos centros e capitais do país. Ceres é uma importante cidade que atende a diversas outras que juntas compõem uma microrregião de 22 municípios, de aproximadamente 231.086 habitantes, conforme dados consolidados pelo Observatório do Mundo do Trabalho (2013).

José e Margarida ${ }^{1}$, personagens das nossas histórias, residem em cidades no entorno de Ceres. Eles têm que se deslocar diariamente de onde moram para estudar. Essa mobilidade é um aspecto que comparece em seus textos e parece ter influência sobre suas experiências formativas.

Margarida reside junto a seu pai na zona rural de Carmo do Rio Verde - GO, uma cidade que fica a $15 \mathrm{~km}$ de Ceres. Duas questões relacionadas à moradia entram em cena na sua história: seu pai, idoso, por preocupar-se com sua segurança a acompanha todos os dias ao ponto de ônibus; e a falta de acesso à internet e outras tecnologias, já que moram em uma fazenda e o sinal não alcança sua residência.

Na primeira versão do texto (antes do retorno aos entrevistados) a falta de acesso à internet foi um fator de desconforto para Margarida, o que a fez apontar isto como uma das dificuldades que enfrenta, ao dizer que para fazer as pesquisas utiliza os livros e, segundo ela, esse processo demora muito. Porém, quando retornamos o texto para que fizesse a releitura, Margarida corrigiu e acrescentou informações. 
$\mathrm{Na}$ segunda versão (revisada pela entrevistada) Margarida contou que hoje continua não tendo acesso à internet em sua residência, devido à falta de recursos financeiros para bancar a instalação de uma antena receptora de sinal. Lembrando que além de ser dona de casa, ela trabalha revendendo semi-jóias. No entanto, disse que adquiriu novo celular e notebook a fim de utilizá-los para fazer pesquisas enquanto está nas dependências do IF Goiano. Ressaltamos que a instituição oferece acesso livre à internet, via wifi, aos estudantes e aos servidores.

Interpretamos na história de Margarida que ao que parece o acesso à internet é uma questão que a incomoda, já que na primeira versão ela declarou que por vezes se sentiu excluída pelo fato de não ter esse acesso e diz que isso é muito difícil. Enquanto que, na segunda versão, a situação se modificou ao ter contato com outros recursos (celular e notebook) e assim, pôde buscar novas informações na rede, conseguiu se comunicar melhor e interagir mais com os colegas. Tudo isto ela atribuiu ao acesso à internet.

Na história de José, frequentar o curso de Ciências Biológicas é a realização de um sonho que foi abandonado no ano de 1982. Na época, José cursava Letras Modernas - Inglês na Universidade Federal de Goiás, em Goiânia. Porém, segundo ele, naquele momento a universidade pública brasileira não era voltada para os interesses dos estudantes pobres, que tinham que trabalhar para se manterem fora de sua cidade de origem. Este era o caso de José, que encontrou na presença do IF Goiano na cidade de Ceres a oportunidade de retomar os estudos e cursar o Ensino Superior perto de sua casa, Rianápolis-GO.

Percebemos que a presença do Instituto em Ceres trouxe consigo não somente o acesso à educação pública, mas a retomada de sonhos adormecidos para aqueles que como José, não tinham condições de sair de sua cidade natal e de se manter na capital. Apesar de ainda ter que se locomover de moto diariamente de Rianápolis, cuja distância até Ceres é de $21 \mathrm{~km}$, José persevera no curso reconhecendo o valor da instituição e o quanto melhorou sua dignidade e autoestima.

De modo geral, é uma tendência entre os estudantes mais velhos do curso residir em outras cidades, poucos sujeitos entrevistados são de Ceres. A maioria mora em outros municípios ${ }^{2}$ : Carmo do Rio Verde, São Patrício, Rubiataba, Santa Isabel, Rianápolis e Itapaci. Este dado aponta para a abrangência de ação do IF Goiano que foi criado com o intuito de atender Ceres e as outras cidades da região. Além de reforçar o aspecto político que legitima a presença desta instituição como um importante meio de acesso à educação e de mudança da realidade local. 
O período de escolarização anterior à entrada no curso de Ciências Biológicas apareceu nas histórias de José e Margarida como componentes que configuram suas experiências formativas atuais. Como os demais estudantes mais velhos entrevistados nossos personagens principais também estudaram em escolas públicas durante a Educação Básica. Porém, eles interpretam o que viveram de modo diferente.

Margarida relaciona suas dificuldades no curso superior à Educação Básica, principalmente à Educação de Jovens e Adultos (EJA) durante o Ensino Fundamental II. Ela interpreta esta falta de base ao fato de que, na época, nas escolas rurais não haviam professores especializados.

$\mathrm{Na}$ história de José nos pareceu que conciliar trabalho e estudos é uma questão persistente, já que abandonou dois outros cursos superiores, Letras e Gestão Ambiental, também por tal motivo. Naqueles tempos, trabalhava à noite, até alta madrugada, em um departamento de um banco e tinha que frequentar as aulas no período matutino, ia com sono, disse que era complicado trabalhar e ter que cursar disciplinas nos outros turnos. Atualmente, enquanto estuda no IF Goiano continua conciliando trabalho e estudos. Atua como serventuário no Tribunal de Justiça do Estado de Goiás durante o dia, na cidade de Rialma $-\mathrm{GO}^{3}$ e frequenta as aulas no noturno, em Ceres.

Uma experiência perpassa de modo generalizado as histórias dos estudantes mais velhos: a reprovação. Como ilustrado em suas falas, muitos têm dificuldades relacionadas aos conteúdos das disciplinas e, como consequência, vivem a experiência de serem reprovados, motivo pelo qual alguns até pensaram em desistir do curso.

$\mathrm{Na}$ história de José, apesar das reprovações constantes, ficou claro que tem encontrado motivação para prosseguir. Ele trouxe à memória uma professora que teve papel decisivo, fazendoo acreditar em seu potencial, reanimando-o e dando-lhe força para seguir adiante. De modo amplo, dentre as dificuldades que foram superadas, José relembrou ainda da falta de manutenção na estrada que dá acesso ao Campus Ceres, na qual havia buracos na pista, e como vinha de moto à noite enfrentou trânsito e correu muitos riscos, principalmente em dias chuvosos.

A idade de José, 61 anos, apareceu para ele na segunda versão de seu texto como uma dificuldade que enfrenta no curso. Ele levou este aspecto em consideração quando disse não ter mais facilidade em assimilar informação, nem possuir uma visão de qualidade, como era na juventude em que não precisava usar óculos. Outro fato importante foi lembrado: desde a infância tem problemas com a memória recente, contou sobre um acontecimento específico no qual 
esqueceu em casa um trabalho acadêmico que tinha feito, quando se deu conta de que tinha trazido para o IF Goiano apenas as obras consultadas, o que o levou a nota zero na atividade.

A presença de José no curso é possível também pelo apoio que recebe da família, ainda que em certas ocasiões, nos momentos em que ele chamou de "desventura em alguma disciplina", sua esposa o tenha advertido que deveria ter estudado enquanto era jovem, e ele disse dar toda razão a ela.

Entendemos que tais situações apresentadas por José parecem ter funcionado como momentos decisivos que serviram como motivação, dando ânimo quando as forças pareciam se acabar diante de uma reprovação, das condições ruins para locomoção ou da desaprovação de sua esposa.

As reprovações nas disciplinas de Física, Química e Biologia Celular marcaram a história de Margarida, e segundo ela, estiveram ligadas à sua formação de nível básico e a um problema familiar. Ela relembrou, na segunda versão do texto, que na época do primeiro ano do curso (momento em que ocorreram tais reprovações) um de seus familiares sofreu um grave acidente, fato que a deixou abalada e a fez despender tempo colaborando na recuperação de quem ela considerava como filho. Lembrando que Margarida é solteira e não possui filhos.

Há nas duas histórias o aparecimento de "motivos", termo obtido em Josso (2010, p. 73) derivado "das artes e da literatura como meios dos quais se manifestou ou tomou forma a dinâmica do sujeito", em outras palavras é aquilo que compareceu recorrentemente nos textos, que tem aspecto de repetição, que marca e atravessa a obra. Dois principais motivos puderam ser depreendidos: a) a dialética entre o individual e o coletivo; b) a demarcação de um modo de conceber o curso superior como superação dos dramas vividos ao longo da vida.

$\mathrm{Na}$ dialética individual/coletivo, a relação com os estudantes mais jovens e com os professores apareceu na história de Margarida como algo positivo. Disse conviver na sala de aula com alguns alunos de perfil etário parecido com o seu, de 45 anos de idade, e que tais pessoas têm valorizado o estudo nesta fase da vida. Com relação aos professores e à instituição, considera que não tem tratamento diferenciado por ser mais velha, pelo contrário, afirmou que se sente reconhecida, valorizada e motivada para prosseguir.

$\mathrm{Na}$ história de José, a relação com os demais estudantes não é vista de modo tão tranquilo, pois, para ele, sua idade parece ter peso sobre isso. Ele se sente constrangido por ocupar uma vaga que poderia servir a uma pessoa mais jovem, como seus colegas de sala. Parece que aqui entra em 
cena um conflito entre a representação social do estudante universitário jovem e recém-saído da escola, na faixa etária ideal entre 18 e 24 anos, como acontece com $66 \%$ dos licenciandos de Ciências Biológicas do País (GATTI; BARRETTO, 2009) com a sua condição de estudante mais velho, entre 25 e 65 anos de idade. Ao mesmo tempo, José se justifica, talvez como forma de equilibrar o conflito, que se mantém no curso como exercício de um direito adquirido e por sua vontade de concluir o ensino superior.

A representação do estudante universitário como um indivíduo mais jovem evidencia na biografia de José o componente dialético entre o social e o individual. Tal compreensão emerge de Ferrarotti (2010, p. 44) ao considerar que o sujeito "mais do que refletir o social, apropria-se dele, mediatiza-o, filtra-o e volta a traduzi-lo, projetando-se numa outra dimensão, que é a dimensão psicológica da sua subjetividade”. No relato de José, para além do peso das determinações sociais, percebemos a reação singular de um sujeito no sentido de se reequilibrar em meio ao conflito vivido (FONTOURA, 2013).

De mesmo modo, essa sensação conflituosa se estende para a relação de José com os professores. Na segunda versão do texto, ele disse que em decorrência das reprovações que teve em algumas disciplinas e da consequente necessidade de repeti-las, sente que sua presença no curso está ficando cansativa e desgastante para si e para seus professores. Compreendemos que esta percepção parece ser de ordem contextual, fruto de uma representação construída em torno da imagem de um estudante exemplar, logo sem reprovações. Em seguida, José falou que não percebe distinção no tratamento que recebe de seus professores, considerando-os justos em suas avaliações e no modo como lidam com ele. Tal assertiva nos parece como esforço de "integração pacificadora" de situações da sua vida (MOITA, 2013, p. 131).

Ao mergulharmos nos textos biográficos dos estudantes pesquisados tivemos acesso às suas histórias de vida, as quais estão fortemente marcadas pelo componente relacional, como evidencia Dominicé (2010a). Destacamos nas biografias de José e Margarida suas relações com os contextos familiares, escolares e institucionais, demonstrando a pertença desses sujeitos ao seu meio social. Tais contextos são componentes que, a primeira vista, parecem não ter importância, mas que ganham relevância nas histórias individuais, e contribuem para fazê-las avançar e conformar a experiência formativa dos sujeitos.

$\mathrm{Na}$ biografia de Margarida a relação com as condições estruturais disponíveis pelo IF Goiano, como a distância considerável entre as salas de aula e a cantina foi um elemento marcante 
em seu relato. Ela conta que já sentiu fome e não teve como sair para comprar seu lanche, e que muitas vezes, perdeu um pouco de aula quando resolveu descer até a cantina. Ao ter contato com a primeira versão, Margarida acrescentou em seu texto que houve mudança em tal situação, dizendo que hoje é possível encontrar pessoas vendendo lanches no corredor das salas de aula, o que já facilitou para que ela e outras pessoas não fiquem tanto tempo sem se alimentar.

No mesmo sentido, José relatou uma situação que viveu em uma viagem técnica durante o curso. Nesta ocasião específica, percebeu o desdém no comentário do motorista responsável por levá-los até o Herbário da Universidade de Brasília, em um tom que tendia a diminuir os estudantes de Ciências Biológicas. José contou em seu texto, na segunda versão, como lidou com este comentário maldoso, o que acabou demonstrando como atribui sentido ao curso. Frente a tal comentário ele demonstrou a importância da Biologia como uma forma de se viver mais respeitosa para com a natureza e, consequentemente, para com as futuras gerações.

O reconhecimento da Biologia é ao mesmo tempo indicativo da importância de sua formação neste curso. Este parece ser um fio condutor relevante para José, seria um motivo que o faz persistir em uma área de conhecimento que não corresponde ao ser fazer profissional atual, na área do Direito. Em seus textos não evidenciamos uma rivalidade entre sua profissão e a formação em Ciências Biológicas, tendo em vista que são reconhecidas por ele como contextos separados, como realidades possíveis. Ao que parece, a Biologia é vista como um campo de conhecimento apenas separado de uma prática profissional. José contou que não tem aptidão para o magistério e que está em busca de diploma para melhorar sua aposentadoria, porém reconhece que todos esses seis anos na instituição e que o que está aprendendo não será em vão, afirmando que o curso o fez crescer.

Em detrimento das dificuldades enfrentadas pelos personagens de nossas duas histórias, José e Margarida construíram ao longo de seus textos uma imagem positiva, representaram-se como sujeitos vencedores que têm superado condições objetivas adversas. Em suas biografias os sujeitos despenderam esforços em busca de autonomia, principalmente diante das condições desfavoráveis de reprovação, de desaprovação da família, de condições contextuais. Josso (2010) percebe o "motivo" da autonomização/conformização como o "jogo da autonomização desejada face a uma conformização esperada pelo meio ambiente" (JOSSO, 2010, p. 74). É assim que evidenciamos nas histórias a busca pela formação a todo custo, contra as circunstâncias (familiares, estruturais, 
profissionais, escolares) que parecem querer desanimá-los, inclusive a sua própria condição de estudantes mais velhos.

O retorno dos textos aos entrevistados foi um momento para que pudessem ter contato direto com suas histórias de vida. Como consequência disso, ativamos no interior da abordagem biográfica a tentativa de permitir "o indivíduo-sujeito tornar-se ator do seu processo de formação, por meio da apropriação retrospectiva do seu percurso de vida" (NÓVOA, 2013, p. 168). Neste processo de apropriação de seus percursos os personagens de nossas histórias o fizeram tendo como base os diversos "momentos-ruptura" (NÓVOA, 2013, p. 181). Esses momentos foram evocados pelo caráter decisivo que tiveram em suas experiências formativas no curso de formação inicial, além de funcionarem como ativadores de uma imagem positiva sobre si e o curso.

O contar sobre si em uma história de vida insere o sujeito em uma atitude dinâmica simultânea de retrospecção, que é própria dos relatos, e de projeção de si, que é o motor da história, que a conduz adiante (DELORY-MOMBERGER, 2006). É no tempo presente que José e Margarida olharam para o passado e projetaram o futuro. Um passado que se faz presente e um futuro que se presentifica como predição, como se encontra em Ricoeur (2010). É pelo presente que conseguimos ter noção da passagem do tempo, "o que passa é, com efeito, o presente” (RICOEUR, 2010, p. 26). Assim, do passado recordaram-se de imagens reconstruídas no presente, que fizeram sentido em suas trajetórias; do futuro projetado pelo presente, construíram imagens daquilo que estão se tornando, e para onde estão indo.

Em seus textos biográficos, os acontecimentos presentes vividos na formação inicial da Licenciatura têm repercussões em seus projetos futuros. Margarida é otimista em relação a seu futuro, ainda que tenha levado em consideração sua condição de estudante mais velha como um fator limitante, quando disse: “já está um pouco tarde”. No entanto, tal situação não a faz deixar de desejar ir mais longe, como notamos na segunda versão de seu texto. Ela contou que: pretende cursar pós-graduação; ou investir em um novo curso como o de Pedagogia, já que gosta muito de criança; ou se especializar na área da Saúde, este é um dos seus sonhos. Tantas possibilidades vão ganhando consistência à medida que ela investe em sua formação, fazendo confluir os anseios da sua dimensão pessoal com o contexto profissional ou formativo.

Da parte de José, aparentemente a idade também é um fator que foi levado em conta quando projeta seu futuro. Embora reconheça como valorosos os aprendizados obtidos no curso, e ainda atribuí a esta formação a responsabilidade por seu crescimento tanto em conhecimento quanto em 
dignidade e autoestima, José não se vê atuando na área. Ele deseja apenas que o diploma conquistado sirva como realização pessoal e para agregação salarial junto a sua profissão atual. A idade tem relação direta com seu desejo pela aposentadoria e a formação em Ciências Biológicas se tornou um meio viabilizador para isto.

Se levarmos em conta os desejos futuros de todos os estudantes mais velhos entrevistados na pesquisa percebemos que querem concluir o curso, reafirmar sua capacidade, perseverar em superar as dificuldades, conviver com diferentes idades, enfrentar preconceitos, e quem sabe atuar como professores. Isto mesmo, para muitos, o magistério parece algo distante e secundário, e só o fato de estarem presentes em uma graduação já faz parte da realização de um desejo e como fonte de satisfação pessoal.

Neste exercício interpretativo, nós investigadores nos convertemos naqueles que construíram e contaram a história por meio de um relato onde frequentemente se pôde ouvir nossa voz, nossas interpretações (BOLÍVAR, 2002, p. 19). Mas, tomamos o cuidado de fazê-la junto aos argumentos, considerações e autointerpretações de nossos pesquisados. Encontramos em Fontoura (2013) um aporte que reforça o que realizamos, em termos de "apresentação sintética de um discurso único, enquanto trabalho que justapõe, associa e combina os vários relatos de vida"; e, por isso, fizemos constantemente referências aos estudantes biografados.

Em nossa interpretação tivemos como finalidade encontrar afinidades e assinalar diferenças (GEERTZ, 2013) com o intuito de produzir uma paisagem, ainda que provisória, do que é a experiência formativa dos estudantes mais velhos do curso de Ciências Biológicas do IF Goiano Campus Ceres.

\section{CONSIDERAÇÕES FINAIS}

Os estudantes mais velhos do curso de Ciências Biológicas do IF Goiano - Campus Ceres contaram suas histórias de vida por meio de um exercício de reflexão sobre si e, ao mesmo tempo, sobre a experiência vivida em sua formação inicial, no momento presente. Neste processo, "durante o ato narrativo, o sujeito se configura segundo uma hipótese de si mesmo que advém da multiplicidade de possibilidades que constituem seu horizonte e que toma provisoriamente como aceitável ou suficientemente boa”. (DELORY-MOMBERGER, 2006, p. 364).

Em outras palavras, interpretamos que as biografias revelaram uma versão coerente que os sujeitos biografados construíram sobre si mesmos. A partir de suas histórias os sujeitos ganharam

\begin{tabular}{l|l|l|l|l|l} 
C Revista Triângulo & Uberaba, Minas Gerais & v.12 & n.1 & p. 3-23 & 2019 \\
\hline
\end{tabular}


existência, se sintonizaram com sua formação, se atualizaram, revisitaram as imagens que os constituem. São imagens de um tempo vivido consigo mesmo, com outras pessoas e com diferentes contextos, indicando que "a formação é feita da presença de outrem” (DOMINICÉ, 2010a, p. 94). Mais do que isto, os textos biográficos mostraram como os indivíduos analisam e percebem a realidade, como organizam suas experiências e dão sentido ao que se vive e ao mundo (DELORYMOMBERGER, 2010).

Nos textos de José e Margarida evidenciamos que um dos sentidos atribuídos à formação inicial em nível superior é a oportunidade para melhorar de vida, melhorar seu status social e, consequentemente, sua imagem perante a sociedade. A busca pelo diploma enlaça seus desejos pessoais ao contexto da licenciatura. Segundo Moita (2013, p. 136) "a formação inicial se torna um tempo/espaço determinante" em suas formações. E, inevitavelmente, agrega aprendizagens às suas experiências, aprendizagens que não se dão descoladas de seus anseios e de suas dimensões pessoais.

Concluímos que a presença do IF Goiano trouxe como efeito a possibilidade de acesso à educação pública, realizada de maneira mais próxima da realidade da vida dos estudantes que moram na microrregião de Ceres. Com isso, o curso de Licenciatura em Ciências Biológicas tem transformado a forma como os alunos mais velhos vivem sua formação, ou melhor, como se relacionam com essa formação. No caso de Margarida, demandou buscar novos conhecimentos mais ligados à tecnologia. Para José, representou o reencontro com o sonho adormecido de concluir um curso superior.

Nossa apropriação da abordagem biográfica abriu possibilidades para pensarmos a formação de adultos, especialmente, a formação de professores de Ciências e Biologia, à medida que realizamos registro, resgate e documentação da "voz" do professor (GOODSON, 2013), em nosso caso, a voz do futuro docente. Buscamos instituir um jeito de pensar a formação de adultos respeitando suas vontades, seus saberes experienciais, dando-lhes o poder de tomar para si a responsabilidade de sua formação. Com tudo isso, almejamos encontrar nos textos biográficos os sentidos para as experiências formativas vividas ao longo da vida.

Diferente do senso comum, defendemos que "os programas ditos de formação não estão na origem do que os adultos aprendem, que seus conhecimentos resultam de uma rede de fontes de informação" (DOMINICÉ, 2010a, p. 95). O que se torna expressivo para o indivíduo em formação 
são as experiências que viveu ao longo da vida e o quanto elas lhes formativas, dito de outra forma, o quanto elas lhes ensinaram algo que transformou sua maneira de ser.

Nos estudos biográficos, segundo Nóvoa (2010) ao recolhermos uma história de vida de um ator social, introduzimo-nos inevitavelmente, na vida social de um grupo e/ou coletividade. É daí que as duas histórias biografadas são emblemas de um coletivo, aqui chamado de "estudantes mais velhos" do curso de Ciências Biológicas do IF Goiano - Campus Ceres. São relatos ao mesmo tempo individuais e sociais, conectados aos conflitos e dramas vividos que se estendem ao grupo como um todo.

Um dos trunfos encontrados no exercício de transformar as entrevistas em textos biográficos, passando pelo retorno dos textos aos entrevistados, foi a possibilidade de compreender a forma como os sujeitos se autointerpretam e constroem suas histórias em torno dos diferentes acontecimentos. Percebemos que em suas histórias os sujeitos buscaram relações, explicações e justificativas para as experiências vividas, encontrando nestas os elementos que lhes foram formativos. Ao mesmo tempo em que compreenderam a si próprios e o contexto de sua formação.

\section{Notas}

1. Utilizamos nomes fictícios a fim de preservar a identidade dos participantes, em conformidade ao Parecer $\mathrm{n}$. 1.584623, aprovado pelo Comitê de Ética em Pesquisa.

2. Distância dos municípios em relação à Ceres: São Patrício (30 km); Rubiataba (46 km); Santa Isabel (25 km); Itapaci $(51 \mathrm{~km})$.

3. Rialma e Ceres são duas cidades separadas por uma ponte que passa sobre o Rio das Almas, estão distantes apenas $3 \mathrm{~km}$.

\section{REFERÊNCIAS}

BAUER, Martin W.; GASKELL, George (Orgs.). Pesquisa qualitativa com texto, imagem e som: um manual prático. 13 ed. Petrópolis, RJ: Editora Vozes, 2015.

BOLÍVAR, Antonio. “De nobis ipsis silemus?”: Epistemología de la investigación biográficonarrativa en educación. Revista Electrónica de Investigación Educativa, v.1, n. 4, p. 41-62, 2002.

BRASIL. Lei $n^{0}$ 11.892, de 29 de dezembro de 2008. Institui a Rede Federal de Educação Profissional, Científica e Tecnológica, e dá outras providências. Diário Oficial da União, Brasília, DF, 30 dez. 2008. Disponível em: < http://www.planalto.gov.br/ccivil_03/_ato20072010/2008/lei/111892.htm> Acesso em: 29 de jun. 2018.

DELORY-MOMBERGER, Christine. Abordagens metodológicas na pesquisa biográfica. Revista Brasileira de Educação, v. 17, n. 51, p. 523-536, set.-dez. 2012. 
. Investigación biográfica em educación: orientaciones y territorios. In: SOUZA, E. C.; PASSEGGI, M. C. (Orgs.) Memoria docente, investigación y formación. Buenos Aires: Editorial de la Facultad de Filosofía y Letras Universidad de Buenos Aires, 2010. p. 25-45.

. Formação e socialização: os ateliês biográficos de projeto. Educação e Pesquisa, v. 32, n. 2, p. 359-371, 2006.

DOMINICÉ, Pierre. O processo de formação e alguns dos seus componentes relacionais. In: NÓVOA, A.; FINGER, M. (Orgs.) O método (auto)biográfico e a formação. São Paulo: Paulus, 2010a. p. 143-154.

A biografia educativa: instrumento de investigação para a educação de adultos. In: NÓVOA, A.; FINGER, M. (Orgs.) O método (auto)biográfico e a formação. São Paulo: Paulus, 2010b. p. 189-222.

FERRAROTTI, Franco. Sobre a autonomia do método autobiográfico. In: NÓVOA, A.; FINGER, M. (Orgs.) O método (auto)biográfico e a formação. São Paulo: Paulus, 2010. p. 31-58.

FONTOURA; Maria Madalena. Fico ou vou-me embora? In: NÓVOA, A. (Orgs.) Vidas de professores. 2 ed. Porto: Porto Ed., 2013. p. 171-198.

GATTI, Bernardete Angelina (Coord.); BARRETTO, Elba Siqueira de Sá. Professores do Brasil: Impasses e Desafios. Brasília: Unesco, 2009. Disponível em: $<$ http://unesdoc.unesco.org/images/0018/001846/184682por.pdf $>$. Acesso em: 29 de jun. 2018.

GEERTZ, Clifford. O saber local: novos ensaios em Antropologia Interpretativa. 12. ed. Petrópolis, RJ: Editora Vozes, 2013.

GOODSON, Ivor F. Dar voz ao professor: as histórias de vida dos professores e seu desenvolvimento profissional. In: NÓVOA, A. (Org.) Vidas de professores. 2. ed. Porto: Porto Ed., 2013. p. 63-78.

IBGE. Instituto Brasileiro de Geografia e Estatística. 2010. Disponível em: < https://cidades.ibge.gov.br/brasil/go/ceres/panorama> Acesso em: 29 jun. 2018.

JOSSO, Marie-Christine. Da formação do sujeito ao sujeito da formação. In: NÓVOA, A.; FINGER, M. (Orgs.) O método (auto)biográfico e a formação. Natal: EDUFRN; São Paulo: Paulus, 2010. p. 59-79.

LARROSA, Jorge. Tremores: escritos sobre experiência. Belo Horizonte: Autêntica, 2015.

MOITA, Maria da Conceição. Percursos de formação e de transformação. In: NÓVOA, A. (Org.) Vidas de professores. 2. ed. Porto: Porto Ed., 2013. p. 111-140.

NÓVOA, António. (Org.). Vidas de professores. 2. ed. Porto: Porto Ed., 2013. 
. A formação tem que passar por aqui: as histórias de vida no Projeto Prosalus. In: NÓVOA, A.; FINGER, M. (Orgs.) O método (auto)biográfico e a formação. Natal: EDUFRN; São Paulo: Paulus, 2010. p. 155-188.

; FINGER, M. (Orgs.). O método (auto)biográfico e a formação. Natal: EDUFRN; São Paulo: Paulus, 2010.

OBSERVATÓRIO DO MUNDO DO TRABALHO. Estudos e pesquisas econômicas, sociais e educacionais sobre as microrregiões do estado de Goiás - microrregião de Ceres. Goiânia, 2013. Disponível em: < https://www.ifg.edu.br/attachments/article/493/microrregiao_ceres.pdf > Acesso em: 29 jun. 2018.

RICOEUR, Paul. Tempo e narrativa. São Paulo: Editora WMF Martins Fontes, 2010, t. 1.

\begin{tabular}{|l|l|}
\hline & Recebido em: 7 Mar. 2018 \\
\hline & Aprovado em: 18 Abr. 2019 \\
\hline
\end{tabular}

